Article

\title{
Nukuhivensiums, Indolo[2,3-a]quinoliziniums from the Marquesan Plant Rauvolfia nukuhivensis
}

\author{
Nicolas J. Martin ${ }^{1}$, Soizic Prado ${ }^{2}$, Gael Lecellier ${ }^{1}$, Olivier P. Thomas ${ }^{3 * *}$ and \\ Phila Raharivelomanana ${ }^{1, *}$
}

1 EIMS Laboratory UMR 241 EIO, University of French Polynesia, 98702 Faa'a, Tahiti, French Polynesia; E-Mails: Nicolas.martin@upf.pf (N.J.M.); Gael.lecellier@upf.pf (G.L.)

2 MCAM Laboratory UMR 7245 CNRS, National Museum of Natural History, 63 rue Buffon, 75005 Paris, France; E-Mail: Sprado@mnhn.fr

3 Nice Institute of Chemistry UMR 7272 CNRS-PCRE, University of Nice-Sophia Antipolis, Parc Valrose, 06108 Nice, France

* Authors to whom correspondence should be addressed; E-Mails: olivier.thomas@ unice.fr (O.P.T.); phila.raharivelomanana@upf.pf (P.R.); Tel.: +33-04-9207-6134 (O.P.T.); Fax: +33-04-9207-6189 (O.P.T.); Tel.: +689-803-813 (P.R.); Fax: +689-803-804 (P.R.).

Received: 13 September 2012; in revised form: 7 October 2012 / Accepted: 9 October 2012 / Published: 12 October 2012

\begin{abstract}
The first phytochemical inspection of the Marquesan endemic plant Rauvolfia nukuhivensis led to the isolation and structure characterization of two new indolo[2,3-a]quinolizinium derivatives named nukuhivensium (1) and $N_{12}$-methylnukuhivensium (2). They feature an aromatic indolo[2,3- $a$ ]quinolizinium core, substituted at $\mathrm{C}-2$ by a $n$-propyl group, which is unusual in this family of alkaloid derivatives. The structure elucidation was performed on the basis of NMR spectroscopy and especially by interpretation of 2D HMBC correlations. A biosynthetic pathway is proposed on the basis of known enzymatic transformations for this family of natural products. These compounds exhibited low antimicrobial activities.
\end{abstract}

Keywords: alkaloid; Rauvolfia; antimicrobial; indoles; biosynthesis 


\section{Introduction}

The highly extended geographic distribution of French Polynesia in the Pacific Ocean has resulted in a relatively high ratio of endemic species spread over the plethora of islands constitutive of this territory, whose distance from the continents may favor the "insular syndrome" leading to more speciation processes [1]. The Marquesas archipelago is one of the most isolated archipelagos of French Polynesia, which have a very original flora within a high endemicity [2,3]. Among them, the plant Rauvolfia nukuhivensis (Apocynaceae), locally called "tueiao", is endemic of the Marquesas archipelago and more precisely of the small island of Nuku Hiva. Although this plant is still used in traditional medicine as a gynecological antiseptic [4], no phytochemical study has been reported so far. Over-exploited because of the frequent use of its bark (macerate) by local communities, the plant is now classified as a critically endangered species, and the description of its chemical constituents is urgently needed before its extinction [5]. Plants of the genus Rauvolfia are well known for their prolific biosynthesis of structurally diverse bioactive indole alkaloids, among them ajmaline and its plethora of structural analogues [6]. Nowadays, the biosynthetic genes of these biologically important alkaloids have been identified, which is an important step towards a commercial use of these compounds [7-9]. Some phytochemical work has been previously undertaken on Pacific species of the genus Rauvolfia. The Scheuer group identified serpentinine, ajmaline, sandwicine, sandwicencine, tetraphylline, tetraphyllicine and mauiensine from the Hawaiian spp. Rauvolfia sandwicensis and $R$. mauiensis [10,11]. Later, the Sevenet group identified ajmaline, but not reserpine, in some endemic species of the genus Rauvolfia from New Caledonia [12].

Within the framework of our continued interest in the phytochemical study of endemic and endangered species of French Polynesia, two original indolo[2,3-a]quinolizinium derivatives named nukuhivensium (1) and $N_{12}$-methylnukuhivensium (2) were isolated from the Polynesian sp. Rauvolfia nukuhivensis (Figure 1). We report herein the isolation and structure elucidation of these new derivatives, as well as their antimicrobial activities.

Figure 1. Structures of natural indolo[2,3-a]quinoliziniums.

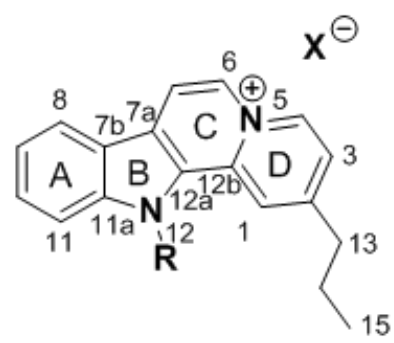

$\mathrm{R}=\mathrm{H} \quad$ Nukuhivensium (1)

$\mathrm{R}=\mathrm{Me} \mathrm{N}_{12}$-methylnukuhivensium (2)

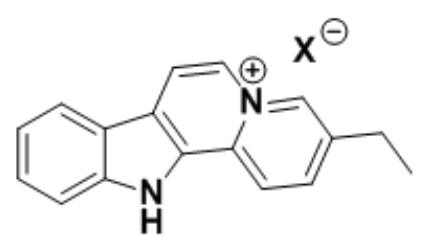

Flavopereirine

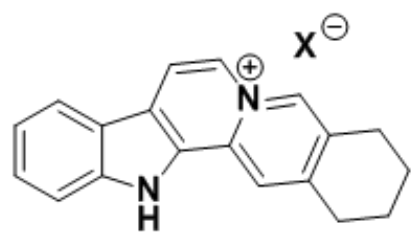

Sempervirine

\section{Results and Discussion}

The stem bark of Rauvolfia nukuhivensis was extracted three times with ethanol and the crude extract was submitted to two subsequent fractionation processes, first by reversed phase and then by 
normal phase chromatography, to yield two main fractions containing alkaloids as revealed by TLC. Purification of one fraction by reversed phase HPLC led to the isolation of both compounds $\mathbf{1}$ and $\mathbf{2}$ in their pure form.

The molecular formula of $\mathbf{1}$ was determined as $\mathrm{C}_{18} \mathrm{H}_{17} \mathrm{~N}_{2}{ }^{+}$by HRESIMS. The ${ }^{1} \mathrm{H}-\mathrm{NMR}$ data (Table 1) suggested the presence of a polyaromatic system substituted by an $n$-propyl group corresponding to the signals at $\delta_{\mathrm{H}} 1.12\left(\mathrm{t},{ }^{3} \mathrm{~J}=7.5 \mathrm{~Hz}, \mathrm{H}_{3}-15\right), 1.94\left(\mathrm{tq},{ }^{3} \mathrm{~J}=7.7\right.$ and $\left.7.5 \mathrm{~Hz}, \mathrm{H}_{2}-14\right)$ and $3.06\left(\mathrm{t},{ }^{3} \mathrm{~J}=7.7 \mathrm{~Hz}\right.$, $\mathrm{H}_{2}$-13) ppm which were clearly COSY correlated. Inspection of the chemical shifts of the resulting protons and carbons indicated that the rest of the molecule was polyaromatic. The presence of heterocyclic aromatic systems was deduced from the high deshielding of some resonating protons.

Table 1. ${ }^{1} \mathrm{H}(500 \mathrm{MHz})$ and ${ }^{13} \mathrm{C}(125 \mathrm{MHz}) \mathrm{NMR}$ data for compounds $\mathbf{1}$ and $\mathbf{2}$ in $\mathrm{CD}_{3} \mathrm{OD}$.

\begin{tabular}{|c|c|c|c|c|c|}
\hline \multirow{2}{*}{ Position } & \multicolumn{3}{|l|}{1} & \multicolumn{2}{|l|}{2} \\
\hline & $\delta_{\mathrm{H}}$, mult $(J$ in Hz$)$ & $\delta_{\mathrm{C}}$, mult & HMBC $(\mathbf{H} \rightarrow \mathrm{C})$ & $\delta_{\mathrm{H}}$, mult $(J$ in $\mathrm{Hz})$ & $\delta_{\mathrm{C}}$, mult \\
\hline 1 & $8.65, \mathrm{~s}$ & $120.5, \mathrm{CH}$ & $13,3,6,12 \mathrm{a}, 12 \mathrm{~b}$ & $8.96, \mathrm{~s}$ & $121.5, \mathrm{CH}$ \\
\hline 2 & & $154.4, \mathrm{C}$ & & & 154.1, C \\
\hline 3 & $7.83, \mathrm{~d}(7.0)$ & $124.4, \mathrm{CH}$ & $4,1,13$ & $7.86, \mathrm{~d}(7.0)$ & $123.9, \mathrm{CH}$ \\
\hline 4 & $9.19, \mathrm{~d}(7.0)$ & 137.6, CH & $3,6,2,12 b$ & $9.24, \mathrm{~d}(7.0)$ & $138.4, \mathrm{CH}$ \\
\hline 6 & $8.84, \mathrm{~d}(7.0)$ & $128.1, \mathrm{CH}$ & $7,7 \mathrm{a}, 12 \mathrm{~b}, 4$ & $8.90, \mathrm{~d}(7.0)$ & $128.1, \mathrm{CH}$ \\
\hline 7 & $8.61, \mathrm{~d}(7.0)$ & 117.2, $\mathrm{CH}$ & $7 b, 6,12 a, 12 b$ & $8.66, \mathrm{~d}(7.0)$ & $116.8, \mathrm{CH}$ \\
\hline $7 \mathrm{a}$ & & $125.0, \mathrm{C}$ & & & $125.6, \mathrm{C}$ \\
\hline $7 b$ & & $122.5, \mathrm{C}$ & & & $128.9, \mathrm{C}$ \\
\hline 8 & $8.36, \mathrm{~d}(8.0)$ & $123.3, \mathrm{CH}$ & $11,7 \mathrm{~b}, 7 \mathrm{a}$ & $8.41, \mathrm{~d}(8.0)$ & $122.8, \mathrm{CH}$ \\
\hline 9 & $7.50, \mathrm{dd}(8.0 ; 7.0)$ & $122.9, \mathrm{CH}$ & $11,8,10,11 \mathrm{a}, 7 \mathrm{~b}$ & $7.54, \mathrm{dd}(8.0,7.0)$ & $123.5, \mathrm{CH}$ \\
\hline 10 & $7.74, \mathrm{dd}(8.0 ; 7.0)$ & $131.0, \mathrm{CH}$ & $8,7 \mathrm{~b}$ & $7.83, \mathrm{dd}(8.0,7.0)$ & $131.2, \mathrm{CH}$ \\
\hline 11 & $7.84, \mathrm{~d}(8.0)$ & 113.6, CH & $9,7 \mathrm{~b}, 11 \mathrm{a}$ & $7.95, \mathrm{~d}(8.0)$ & $112.1, \mathrm{CH}$ \\
\hline $11 \mathrm{a}$ & & 143.3, C & & & $144.9, \mathrm{C}$ \\
\hline 12 & & & & $4.58, \mathrm{~s}$ & $34.6, \mathrm{CH}_{3}$ \\
\hline $12 \mathrm{a}$ & & $131.7, \mathrm{C}$ & & & $131.4, \mathrm{C}$ \\
\hline $12 b$ & & 134.3, C & & & $135.2, \mathrm{C}$ \\
\hline 13 & $3.06, \mathrm{t}(7.7)$ & $38.6, \mathrm{CH}_{2}$ & $14,15,2,1,3$ & $3.09, \mathrm{t}(7.7)$ & $38.7, \mathrm{CH}_{2}$ \\
\hline 14 & $1.94, \operatorname{tq}(7.7 ; 7.5)$ & $23.9, \mathrm{CH}_{2}$ & $15,13,2$ & $1.93, \mathrm{tq}(7.7,7.5)$ & $24.4, \mathrm{CH}_{2}$ \\
\hline 15 & $1.12, \mathrm{t}(7.5)$ & $14.0, \mathrm{CH}_{3}$ & 14,13 & $1.12, \mathrm{t}(7.5)$ & $14.0, \mathrm{CH}_{3}$ \\
\hline
\end{tabular}

A careful inspection of the HMBC spectrum allowed us to unravel the chemical structure of 1. Indeed, the $n$-propyl was located on the para position of a pyridinium ring due to the key $\mathrm{H}_{2}-13 / \mathrm{C}-2 /$ C-1/C-3 HMBC correlations, the $\mathrm{H}_{2}-13 / \mathrm{H}-1 / \mathrm{H}-3{ }^{4} J$ correlations and the ${ }^{3} J$ COSY correlation between the signal at $\delta_{\mathrm{H}} 7.83\left(\mathrm{~d},{ }^{3} J=7.0 \mathrm{~Hz}, \mathrm{H}-3\right)$ and $9.19\left(\mathrm{~d},{ }^{3} J=7.0 \mathrm{~Hz}, \mathrm{H}-4\right) \mathrm{ppm}$, this highly deshielded signal being inferred to the vicinity of the electron withdrawing effect of an ammonium group (Figure 2). The clear H-4/C-3/C-2/C-6/C-12b ${ }^{2} J$ and ${ }^{3} J$ HMBC correlations allowed the assignment of the entire pyridinium D ring as well as the C-6 methine. Starting from this C-6 methine, COSY coupled to the signal at $\delta_{\mathrm{H}} 8.61\left(\mathrm{~d},{ }^{3} \mathrm{~J}=7.0 \mathrm{~Hz}, \mathrm{H}-7\right)$, we were able to build the quinolizinium part of the molecule. Indeed the H-6/C-4/C-12b/C-7/C-7a HMBC correlations yielded the construction of the second pyridinium ring. The pattern of the resulting signals in the ${ }^{1} \mathrm{H}-\mathrm{NMR}$ and COSY spectra was reminiscent of an indole ring with $\delta_{\mathrm{H}} 8.36\left(\mathrm{~d},{ }^{3} \mathrm{~J}=8.0 \mathrm{~Hz}, \mathrm{H}-8\right), 7.50\left(\mathrm{dd},{ }^{3} J=8.0\right.$ and $\left.7.0 \mathrm{~Hz}, \mathrm{H}-9\right)$, 
$7.74\left(\mathrm{dd},{ }^{3} \mathrm{~J}=8.0\right.$ and $\left.7.0 \mathrm{~Hz}, \mathrm{H}-10\right)$ and $7.84\left(\mathrm{~d},{ }^{3} \mathrm{~J}=8.0 \mathrm{~Hz}, \mathrm{H}-11\right) \mathrm{ppm}$. Finally, the indole ring was fused to the second pyridinium at C-12a/C-7a due to the key $\mathrm{H}-7 / \mathrm{C}-7 \mathrm{~b} / \mathrm{C}-12 \mathrm{a} / \mathrm{C}-7 \mathrm{a}$ HMBC correlations. Additional $\mathrm{H}-8 / \mathrm{C}-7 \mathrm{a} / \mathrm{C}-11 \mathrm{a}{ }^{3} J \mathrm{HMBC}$ correlations came to confirm the proposed structure of $\mathbf{1}$.

Figure 2. Key COSY (bold) and $\mathrm{HMBC}(\mathrm{H} \rightarrow \mathrm{C}$, arrow) correlations for $\mathbf{1 .}$

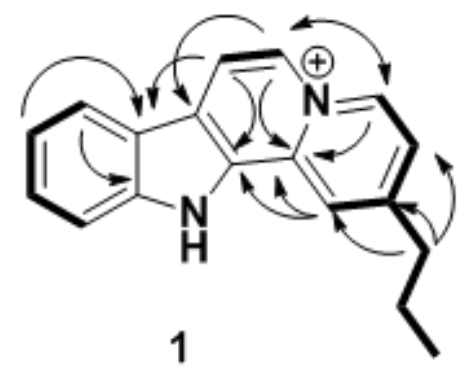

The molecular formula of 2 was determined as $\mathrm{C}_{19} \mathrm{H}_{19} \mathrm{~N}_{2}{ }^{+}$by HRESIMS and suggested the presence of an additional methyl group comparing to 1 . This methyl group was easily located at $N_{12}$ due to the chemical shifts at $\delta_{\mathrm{H}} 4.58\left(\mathrm{~s}, \underline{\mathrm{H}}_{3}-\mathrm{C}\right)$ and $\delta_{\mathrm{C}} 33.6\left(\underline{\mathrm{C}}-\mathrm{H}_{3}\right) \mathrm{ppm}$ (Table 1) which were reminiscent of an aromatic $\mathrm{N}$-substituted methyl group. The deshielding of $\mathrm{H}-1$ was clearly induced by the presence of this methyl at $N_{12}$ and the $\underline{\mathrm{H}}_{3}-\mathrm{C} / \mathrm{C}-11 \mathrm{a} / \mathrm{C}-12 \mathrm{a} \mathrm{HMBC}$ correlations finally confirmed the substitution at $N_{12}$. Compound 2 may be seen as an artifact during our extraction and purification process. Nevertheless, methylation with methanol is quite rare, especially under our mild extraction and purification conditions and the low nucleophilicity of the indole nitrogen.

From a structural point of view, these compounds share a rare indolo[2,3-a]quinolizinium core already found in flavopereirine [13,14] and sempervirine [15], for example (Figure 1). To our knowledge, the presence of an alkyl chain at C-2 was never reported on this aromatic core and this observation raised the question of the biosynthesis of these compounds. While for flavopereirine and sempervirine an oxidative process starting from saturated known analogues can be proposed, the presence of an $n$-propyl moiety at C-2 was very intriguing. Because there was no doubt on the structure of these compounds, we undertook a detailed analysis of known biochemical pathways leading to these new compounds. We suggest that a plausible hypothesis would start from the key and highly reactive intermediate "dialdehyde" derived from strictosidine (Scheme 1) [16]. In other Rauvolfia species, this dialdehyde has been proposed to yield the sarpagan and ajmalan alkaloids via 4,21-dehydro-geissoschizine, which involves an iso-propyl at C-2. Rather than an unlikely rearrangement of these three carbon atoms, we propose that nukuhivensiums could be formed like vallesiachotamine (Scheme 1). Indeed, after an alternative cyclization of "dialdehyde" two subsequent decarboxylative steps could afford the $n$-propyl at C-2 and finally compound $\mathbf{1}$ after additional oxidative steps. Work is ongoing to isolate minor alkaloids from this plant in order to strengthen our biosynthetic hypothesis. 
Scheme 1. Biosynthetic hypothesis for $\mathbf{1 .}$
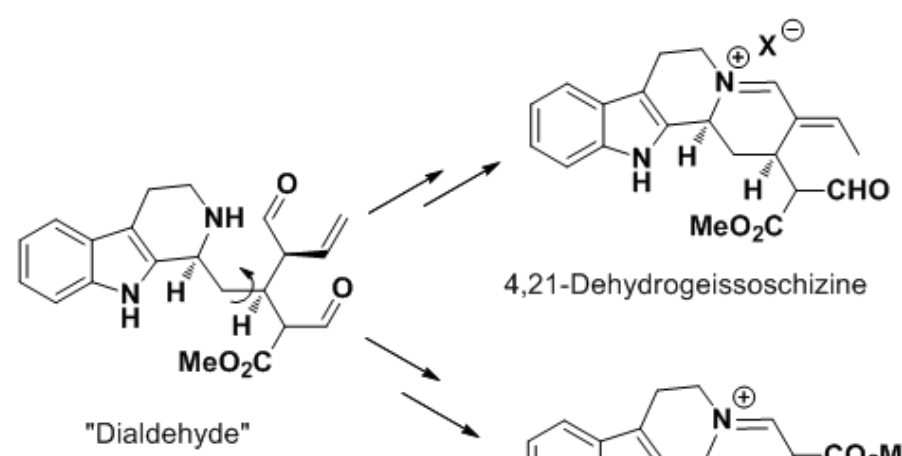

4,21-Dehydrogeissoschizine
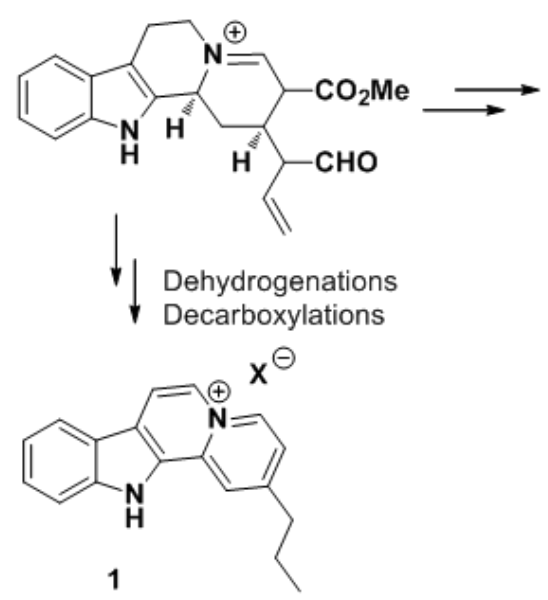

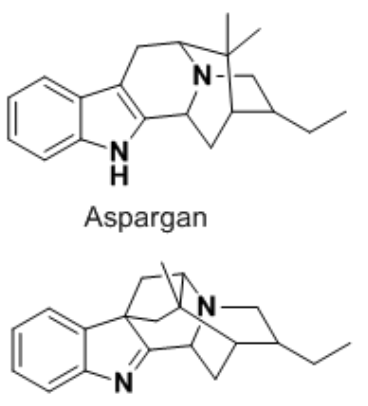

Ajmalan<smiles>C/C=C(/C=O)[C@H]1C[C@H]2c3[nH]c4ccccc4c3CCN2C=C1C(=O)OC</smiles>

Vallesiachotamine

Because extracts of this plant are being used as a gynecological antiseptic, we first decided to assess the antimicrobial potential of these two new derivatives. Compounds $\mathbf{1}$ and $\mathbf{2}$ were evaluated in vitro for their antimicrobial activity against Escherichia coli, Staphylococcus aureus, Candida albicans and Aspergillus niger. Both compounds exhibited low antimicrobial activities against S. aureus and C. albicans (Table 2). Two options can then be proposed: (i) other minor compounds are responsible of an antimicrobial activty related to the ethnopharmocological use of this plant; or (ii) the mode of action related to the gynecological use of this plant is not as antimicrobial agents.

Table 2. Antimicrobial activities of $\mathbf{1}$ and $\mathbf{2 .}$

\begin{tabular}{ccccc}
\hline Compounds & $\begin{array}{c}\text { MIC }_{\mathbf{9 0}} \\
\text { S. aureus } \\
(\boldsymbol{\mu g} / \mathbf{m L})\end{array}$ & $\begin{array}{c}\mathbf{M I C}_{\mathbf{9 0}} \\
\boldsymbol{E} . \text { coli } \\
(\boldsymbol{\mu g} / \mathbf{m L})\end{array}$ & $\begin{array}{c}\mathbf{M I C}_{\mathbf{9 0}} \\
\text { C. } \text { albicans } \\
(\boldsymbol{\mu} \mathbf{g} / \mathbf{m L})\end{array}$ & $\begin{array}{c}\mathbf{M I C}_{\mathbf{9 0}} \\
\text { A. } \text { niger } \\
(\boldsymbol{\mu g} / \mathbf{m L})\end{array}$ \\
\hline $\mathbf{1}$ & 105 & $>150$ & 100 & $>150$ \\
$\mathbf{2}$ & 115 & $>150$ & 100 & $>150$ \\
Tetracycline & 0.5 & 3 & $\mathrm{Nt}$ & $\mathrm{Nt}$ \\
Econazole & $\mathrm{Nt}$ & $\mathrm{Nt}$ & 2.60 & 2.20 \\
\hline
\end{tabular}

$\mathrm{Nt}$ : Non tested. 


\section{Experimental}

\subsection{General}

UV-Vis spectra were recorded by HPLC-DAD. NMR spectra were measured on a Bruker Avance $500 \mathrm{MHz}$ spectrometer with pulsed field gradient and signals were referenced to the residual solvent signals $\left(\mathrm{CD}_{3} \mathrm{OD}\right.$, at $\delta_{\mathrm{H}} 3.31$ and $\left.\delta_{\mathrm{C}} 49.0 \mathrm{ppm}\right)$. HRESIMS data were measured with a LTQ Orbitrap mass spectrometer (Thermo Finnigan). HPLC purification was carried out on a Waters 600 system equipped with a Waters 717 Plus autosampler, a Waters 998 photodiode array detector, and a Sedex 75 evaporative light-scattering detector (Sedere, France).

\subsection{Plant Material}

Rauvolfia nukuhivensis was collected at Maauu in the "Terre Déserte" area on Nuku Hiva Island, Marquesas archipelago, French Polynesia, at $477 \mathrm{~m}$ above sea level and identified by Dr Jean-François Butaud. A voucher specimen (JFB 2808) has been deposited in the Herbarium of French Polynesia.

\subsection{Extraction and Isolation}

The dried bark $(250 \mathrm{~g})$ was ground and extracted three times with $750 \mathrm{~mL}$ of EtOH at room temperature. The maceration was allowed to proceed for $16 \mathrm{~h}$ and then the solvent was filtered and concentrated by evaporation to yield a crude oil. The resulting extract $(21 \mathrm{~g})$ was dissolved by sonication in a mixture of $200 \mathrm{~mL} \mathrm{MeOH} / \mathrm{CH}_{2} \mathrm{Cl}_{2}(1: 1)$ and then filtered before fractionation. This was carried out by vacuum liquid chromatography on $\mathrm{RP}-\mathrm{C}_{18}$ and eluted with solvents of decreasing polarity A, B, C, D, E $\left(\mathrm{H}_{2} \mathrm{O}, \mathrm{H}_{2} \mathrm{O} / \mathrm{MeOH}\right.$ (1:1), $\mathrm{MeOH}, \mathrm{MeOH} / \mathrm{CH}_{2} \mathrm{Cl}_{2}$ (1:1) and $\mathrm{CH}_{2} \mathrm{Cl}_{2}$, respectively). Fraction D, obtained with the $\mathrm{MeOH} / \mathrm{CH}_{2} \mathrm{Cl}_{2}$ eluent, provided $2.82 \mathrm{~g}$ of an oily residue. A portion of fraction D (1.41 g) was further fractionated by normal phase (diol) flash column chromatography using solvents of stepwise increasing polarity: cyclohexane, cyclohexane/EtOAc (3:1), cyclohexane/EtOAc (1:1), cyclohexane/EtOAc (1:3), EtOAc, EtOAc/MeOH (3:1), EtOAc/MeOH (1:1), EtOAc/MeOH (1:3) and $\mathrm{MeOH}$, yielding nine fractions D1 to D9. Purification of D7 (104 mg) was performed by RP-C 18 semi-preparative HPLC (Phenomenex, Luna $5 \mu \mathrm{m} \mathrm{C}_{18}$, $250 \mathrm{~mm} \times 10 \mathrm{~mm}$ ) with a gradient of $\mathrm{MeOH} / \mathrm{H}_{2} \mathrm{O} / \mathrm{TFA}$ (from 70:30:0.1 to 30:70:0.1, flow $3 \mathrm{~mL} \mathrm{~min}^{-1}$ ) to afford pure compounds $\mathbf{1}(4.7 \mathrm{mg})$ and $\mathbf{2}(2.8 \mathrm{mg})$.

Nukuhivensium (1). UV measured by HPLC/DAD (MeOH/ $\left.\mathrm{H}_{2} \mathrm{O} / \mathrm{TFA}\right) \lambda_{\max } 224,241,290,340,382 \mathrm{~nm}$; ${ }^{1} \mathrm{H}$ - and ${ }^{13} \mathrm{C}-\mathrm{NMR}$ see Table 1; HRESIMS $m / z, 261.13953[\mathrm{M}]^{+}$(calcd for $\mathrm{C}_{18} \mathrm{H}_{17} \mathrm{~N}_{2}{ }^{+}, 261.13917$ ).

$\mathrm{N}_{12}$-methylnukuhivensium (2). UV measured by HPLC/DAD (MeOH/ $\left.\mathrm{H}_{2} \mathrm{O} / \mathrm{TFA}\right) \lambda_{\max } 225,237,248$, 287, 335, $393 \mathrm{~nm} ;{ }^{1} \mathrm{H}$ - and ${ }^{13} \mathrm{C}-\mathrm{NMR}$ see Table 1; HRESIMS $\mathrm{m} / \mathrm{z} 275.15417[\mathrm{M}]^{+}$(calcd for $\left.\mathrm{C}_{19} \mathrm{H}_{19} \mathrm{~N}_{2}^{+}, 275.15482\right)$.

\subsection{Biological Evaluations}

Reference strains of Escherichia coli (ATCC 8739) and Staphylococcus aureus subsp. aureus (ATCC 6538) were obtained from the Collection of the Institute Pasteur (Paris, France). Bacterial 
species were cultivated for $24 \mathrm{~h}$ in Luria Bertani medium (LB) at $37{ }^{\circ} \mathrm{C}$. Candida albicans (IBMC Strasbourg) and Aspergillus niger (ATCC 9142) were cultivated at $30{ }^{\circ} \mathrm{C}$ for $48 \mathrm{~h}$ in Sabouraud dextrose medium (Sanofi Diagnostic Pasteur). Briefly, pre-cultures of the tested micro-organisms were made by inoculating $10 \mathrm{~mL}$ of LB and incubating for $24 \mathrm{~h}$ for bacteria or $10 \mathrm{~mL}$ in Sabouraud for $48 \mathrm{~h}$ for fungi. A culture suspension were made by 1/1,000 dilution from preculture and seeded in 96-well microtitration plates. Four microliters of two-fold serial dilutions of each compound $(10 \mathrm{mg} / \mathrm{mL})$ was prepared in $100 \mu \mathrm{L}$ of medium. The plates were incubated at $37{ }^{\circ} \mathrm{C}$ for bacteria and at $30{ }^{\circ} \mathrm{C}$ for fungus. After $24 \mathrm{~h}$, the optical density of the bacterial suspension of each well was measured at $595 \mathrm{~nm}$ using a multiplate reader. Tetracycline and econazole were used as positive controls.

\section{Conclusions}

Endemic plants of the Pacific Islands have been poorly studied phytochemically and several of them are now recognized as endangered species. Several species of the genus Rauvolfia are found on these islands and Rauvolfia nukuhivensis is currently used in traditional medicines by the local communities of the Marquesas islands (French Polynesia). Within a program aiming at protecting this species we decided to study the therapeutical potential of its chemodiversity. While ajmaline derivatives are frequently encountered, we were able to isolate two new indolo[2,3-a]quinolizinium derivatives closely related to sempervirine, but substituted at C-2 by an $n$-propyl alkyl chain. This finding raised the question of the biosynthesis of these two derivatives and we suggest another type of cyclisation of the well known corresponding dialdehyde. Because these compounds were found to exhibit a low antimicrobial activity, we will follow up the description of the metabolome of this species to further identify the bioactive constituents of this folk medicine.

\section{Supporting Information}

Supplementary materials can be accessed at: http://www.mdpi.com/1420-3049/17/10/12015/s1.

\section{Acknowledgments}

This work was supported by a $\mathrm{PhD}$ grant to Nicolas Martin from the "Ministère de l'Enseignement Supérieur et de la Recherche" of the French government. We are thankful to J. F. Butaud and to French Polynesia DIREN department for sample collection, plant material identification and helpful discussions. The authors wish to thank Jean-Marie Guigonis (Plate-Forme Bernard Rossi) for HRESIMS measurements and Marc Gaysinski (Plate-Forme Technologique de Chimie de Nice) for recording the NMR experiments.

\section{References}

1. Guezenec, J.; Moretti, C.; Simon, J.C. Substances Naturelles en Polynésie française (in French); IRD Editions: Montpellier, France, 2006.

2. Lorence, D.H.; Wagner, W.L. Introduction to botany of the marquesas islands: New taxa, combinations, and revisions. PhytoKeys 2011, 4, 1-4. 
3. Florence, J.; Chevillotte, H.; Ollier, C.; Meyer, J.Y. Base de données botaniques Nadeaud de l'herbier de Polynésie française (PAP) (in French). Available online: http://www.herbier-tahiti.pf/ (accessed on 10 October 2012).

4. Suggs, R.C. Marquesan Sexual Behavior: An Anthropological study of Polynesian Practices; Harcourt, Brace: New York, NY, USA,1966.

5. Lorence, D.H.; Butaud, J.F. A reassessment of Marquesan Ochrosia and Rauvolfia (Apocynaceae) with two new combinations. PhytoKeys 2011, 4, 95-107.

6. Lounasmaa, M.; Hanhinen, P. The ajmaline group of indole alkaloids. In The Alkaloids: Chemistry and Biology; Academic Press: San Diego, CA, USA, 2001; Volume 55, pp. 1-87.

7. Yang, L.; Stöckigt, J. Trends for diverse production strategies of plant medicinal alkaloids. Nat. Prod. Rep. 2010, 27, 1469-1479.

8. Stöckigt, J.; Panjikar, S.; Ruppert, M.; Barleben, L.; Ma, X.; Loris, E.; Hill, M. The molecular architecture of major enzymes from ajmaline biosynthetic pathway. Phytochem. Rev. 2007, 6, 15-34.

9. Stöckigt, J. Biosynthesis in Rauwolfia serpentina. Modern aspects of an old medicinal plant. In The Alkaloids: Chemistry and Biology; Academic Press: SanDiego, CA, USA, 1995; Volume 47, pp. 115-172.

10. Scheuer, P.J.; Chang, M.Y.; Fukami, H. Hawaiian plant studies. X. The structure of mauiensine. J. Org. Chem. 1963, 28, 2641-2643.

11. Gorman, M.; Neuss, N.; Djerassi, C.; Kutney, J.P.; Scheuer, P.J. Alkaloids. XIX. Alkaloids of Hawaiian Rauwolfia species. Structure of sandwicine and its interconversion with ajmaline and ajmalidine. Tetrahedron 1957, 1, 328-337.

12. Libot, F.; Miet, C.; Kunesch, N.; Poisson, J.E.; Pusset, J.; Sevenet, T. Plants of New Caledonia. Part 1020. Indole alkaloids from Rauvolfia species of New Caledonia. Ann. Pharm. Fr. 1986, 44, 477-485.

13. Reina, M.; Ruiz-Mesia, W.; Lopez-Rodriguez, M.; Ruiz-Mesia, L.; Gonzalez-Coloma, A.; Martinez-Diaz, R. Indole alkaloids from Geissospermum reticulatum. J. Nat. Prod. 2012, 75, 928-934.

14. Steele, J.C.P.; Veitch, N.C.; Kite, G.C.; Simmonds, M.S.J.; Warhurst, D.C. Indole and $\beta$-Carboline Alkaloids from Geissospermum sericeum. J. Nat. Prod. 2002, 65, 85-88.

15. Gribble, G.W.; Barden, T.C.; Johnson, D.A. A directed metalation route to the zwitterionic indole alkaloids. Synthesis of sempervirine. Tetrahedron 1988, 44, 3195-3202.

16. O'Connor, S.E.; Maresh, J.J. Chemistry and biology of monoterpene indole alkaloid biosynthesis. Nat. Prod. Rep. 2006, 23, 532-547.

Sample Availability: Samples of the compounds 1-2 are available from the authors.

(C) 2012 by the authors; licensee MDPI, Basel, Switzerland. This article is an open access article distributed under the terms and conditions of the Creative Commons Attribution license (http://creativecommons.org/licenses/by/3.0/). 